\title{
Redox hydrogeochemistry of organic rich floodplain exemplified by Ammer river
}

\author{
Evgenii Kortunov ${ }^{1, *}$, Chuanhe $\mathrm{Lu}^{2}$, Richard $\mathrm{Amos}^{3}$, Peter Grathwohl ${ }^{2}$ \\ ${ }^{1}$ Faculty of Geology, Department of Hydrogeology, Lomonosov Moscow State University, GSP-1, \\ Leninskie Gory, Moscow 119899, Russia \\ ${ }^{2}$ University of Tübingen, Center for Applied Geosciences, Hölderlinstr. 12, 72074 Tübingen, \\ Germany \\ ${ }^{3}$ Department of Earth Sciences, Carleton University, 1125 Colonel By Drive, Ottawa, ON K1S 5B6, \\ Canada
}

\begin{abstract}
Diffusive groundwater pollution caused by agricultural and atmospheric inputs is a pressing issue in environmental management worldwide. Various researchers have studied nitrate contamination since the substantial increase of nitrogen fertilization in agriculture starting in the second half of the $20^{\text {th }}$ century. This study addresses large scale reactive solute transport in typical landscapes and aquifers exemplified by geological analogues of southwestern Germany..Fate of nitrate and other solutes (e.g. agricultural nitrate, ammonium, natural sulfate and dissolved organic carbon) was studied in a typical small river floodplain. Reactive transport model of Ammer river floodplain shows that agriculture nitrate is reduced rapidly in the Ammer floodplain sediments. However, there is a potential for geogenic production of ammonium in sediment layers high in organic carbon and peat, which might be a major source of nitrate in the drains. Part of the nitrate in drains and creeks in the Ammer valley thus could be of geogenic origin. Such findings are relevant for regional land and water quality management.
\end{abstract}

\section{Introduction}

Floodplains are common elements in catchments. In temperate climates, they are typically comprised by Pleistocene sands and gravels as well as Holocene peat lenses and loams $[1,2]$ and normally considered as hotspots in the biogeochemical cycle due to high organic matter content [3].

The Ammer floodplain is a part of the Ammer catchment located between Pfäffingen and Tübingen. Hillslopes formed of Gipkeuper mudstones confine the floodplain. At the base, it starts with highly conductive base gravel layer, followed by a low-conductive clay layer and a layered system of calcareous sediments and peat. These layers are overlain by alluvium silt and loam. Top sediments are observed to be highly reduced and the $\mathrm{H}_{2} \mathrm{~S}$ smell was also observed when coring, indicating sulfate reduction, which is possible only when

\footnotetext{
*Corresponding author: ekortunov@gmail.com
} 
nitrate and oxygen are already consumed [4]. The hydraulic connection between the base layer and other layers is still unknown; the general flow direction is along the valley. Relatively high concentrations of nitrate have been observed in the Ammer river $(0.5$ $\mathrm{mmol} / \mathrm{l})$ and drainage channels $(0.2 \mathrm{mmol} / \mathrm{l})$. Concentrations of ammonium found in porewater of the floodplain sediments match molality of the nitrate in the ditches $(0.2$ $\mathrm{mmol} / \mathrm{l})$.

A 2-D fully coupled reactive transport model was set up aiming to answer following questions: 1) What is the fate of nitrate when it enters the sediments of the floodplain? Is it reduced in the sediments or finally collected by drainage channels? 2) What is the influence of the spatial distribution or organic carbon within the floodplain sediments on ammonification and denitrification? 3) What is the source of the nitrate observed in the drains? Is it agricultural nitrate or does it come from natural ammonium produced in organic carbon rich layers in the sediments? 4) Are there any other important reactions except the redox reactions affecting nitrate such as sulfate reduction, mineral precipitation, nitrogen gas trapping, etc.?

\section{Flow model setup}

To get a better insight of the typical floodplain geochemistry as well as determine the fate of nitrate and other solutes in the above-discussed flow system, a fully coupled flow and reactive transport model of the Ammer floodplain was developed. It comprises (from bottom to the top): the gypsum-bearing (highly oxidized) Upper Triassic Gipskeuper mudstones (bedrock), a Pleistocene sand and gravel layer, Holocene organic carbon rich clay and lacustrine calcareous sediments with layers of peat, and alluvial loam on the top (Fig. 1). Drainage channels, installed for agriculture and the Ammer River serves as the only drain for the floodplain groundwater. The numerical model was designed based on the geological settings. Sets of hydraulic parameters were assigned to five homogeneous compartments. Hydraulic parameters were estimated based on grain sizes and observations. The alluvium loam and gravel layers parameters were adapted from the transport study in the Neckar valley [5].

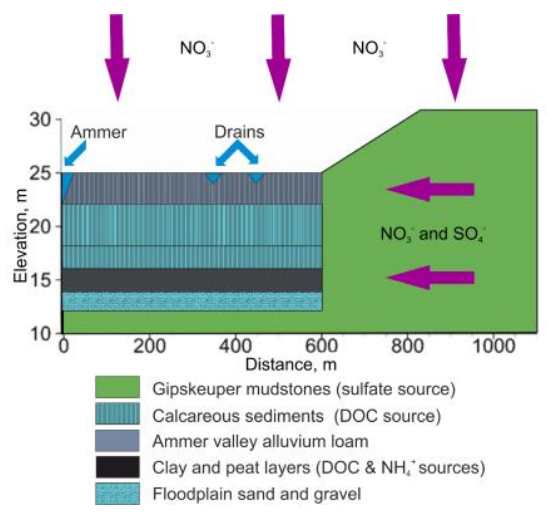

Fig. 1. W-E cross-section and conceptual model of the Ammer valley sediments (vertically exaggerated). Nitrate is applied at the top of the model while ammonification happens in the black clay layer.

The two-dimensional model is 1100 meters long and 36 meters in height. The physical domain was divided into 144 layers and 440 columns resulting in a uniform numerical grid of $25 \times 0.25$ meters. On the top of the model, a fixed flow (Neumann) boundary condition was applied. The steady state flow rate $(200 \mathrm{~mm} / \mathrm{year})$ represents the average annual recharge in the region $[6,7]$. For the Ammer river and the drainage channels, fixed head 
(Dirichlet) boundaries were used with heads of 22 and 23 meters, respectively. Bottom and the right boundary (water divide) were set impermeable.

Due to lack of space, for exact flow and transport parameters as well as for geochemical system used for the reactive transport simulations we recommend to refer to [8].

\section{Results and discussion}

The results of the modeling are presented on Fig. 2.
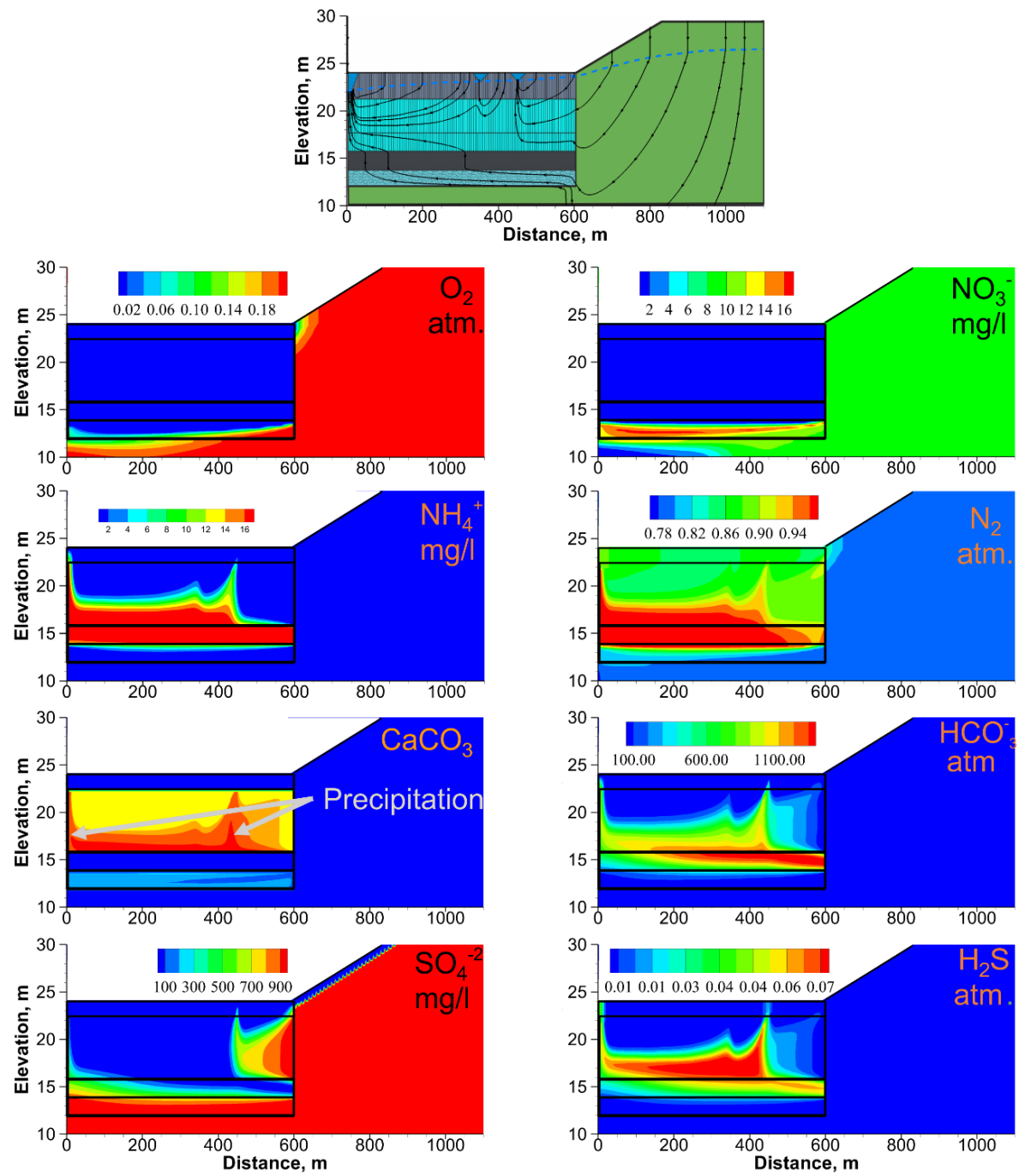

Fig. 2. Results for the Ammer, floodplain model. Top: Flow paths and water table; bottom: simulated quasi steady-state spatial distribution of $\mathrm{O}_{2}, \mathrm{NO}_{3}{ }^{-}, \mathrm{NH}_{4}{ }^{-}, \mathrm{N}_{2}, \mathrm{CaCO}_{3}, \mathrm{HCO}_{3}^{-}, \mathrm{SO}_{4}{ }^{-2}$ and $\mathrm{H}_{2} \mathrm{~S}$ along the transect. Electron acceptors are transported along the gravel layer for long distances. Additional nitrate is produced on the boundary between gravel and clay layers, however, is attenuated again in the clay and silt layers. Sulfate reaches the drain closest to the hillslope and partially the river. Calcite precipitates along the flow paths. 


\subsection{Redox zonation and steep redox gradients}

Steep redox gradients cause sharp transitions from electron acceptors-rich sediments (bedrock mudstones, where are no reduction whatsoever) to electron donor-rich sediments (floodplain). This transition controls the hydrogeochemistry of the whole floodplain and affects reactive transport through it. Mixing under such conditions is only significant in the gravel and sand layer where mixing allows more nitrate to be generated by ammonia, while in the calcareous sediments the supply of reagents is regulated by the flux of the electron acceptors and the release of electron donors from sediments.

\subsection{Possible sources of nitrate in Ammer river and drainage channels}

The high concentration of nitrate below the clay layer might be explained by the ammonium production. Mixing with oxic water (the only area where mixing plays an important role) leads to nitrate production. Thus, geogenic $\mathrm{NH}_{4}{ }^{+}$(generated in the organic rich clay layer) is the additional source of the nitrate in the gravel layer. In contrast, agricultural nitrate is completely attenuated in the reduced parts of the alluvial loam in the floodplain. Thus, agricultural nitrate does not reach the drains and the river. The only option for $\mathrm{NO}_{3}{ }^{-}$and $\mathrm{O}_{2}$ to propagate into the floodplain is after the reduction potential is exhausted at least in some parts of the sediments. This is possible in the presence of the preferred water paths whose existence are unknown. Thus, the nitrate in the drains is predicted to be geogenic: ammonia discharges into the drains and oxidized in the surface water bodies.

\subsection{Potential conductivity changes due to self-cementation of the Ammer floodplain sediments and degassing}

The dissolution of the gypsum from the bedrock produces high concentrations of calcium and sulfate. While the latter one mostly is reduced during transport, the former one is not affected by redox reactions directly. On the other hand, sulfate reduction, denitrification and oxygen reduction all produce $\mathrm{CO}_{2}$ and consume hydrogen ions. Moreover, these processes tend to happen in areas of high flow - thus transport of calcium from the bedrock leads to calcite precipitation. Since the quaternary sediments contain calcareous tuff layers additional calcite precipitation is hard to distinguish, but this would decrease the pore space and thus hydraulic conductivity. Calcite concretions and aggregates of different sizes (up to $1 \mathrm{~cm}$ ) were observed in drilling cores. Another process impacting flow is degassing. Nitrogen gas pressure reaches one bar, which is still lower than the expected water pressure below the river. However, more gas release and increased fertilization (higher concentration of $\mathrm{NO}_{3}{ }^{-}$) can lead to increasing total gas pressure and finally degasification happens. The bubbles of unknown gas have been observed in the draining ditches. Degassing would restrict water flow and could be accounted for in the long-term.

\section{Conclusions}

A two-dimensional reactive transport simulation of solutes in the Ammer river floodplain was performed to get an insight into biogeochemical changes and to determine the potential to attenuate nitrate and sulphate. The gravel base layer acts as a confined aquifer and allows fast transport of contaminants as well as a reactor for electron donors from the black clay layer and electron acceptors from the mudstones. The travel time between this aquifer and the river can vary. Geogenic production of ammonium in high organic layers and peat likely is a major source of nitrate in the river and the ditches. This does correspond to 
nitrate concentrations observed in the drains. As a final point, high pressures of $\mathrm{N}_{2}$ are observed in the model along with precipitation of calcite on the flow paths. These processes can affect the flow field in larger timescales and should be studied further. Nitrate and other contaminants, which are degraded under reducing conditions, are readily reduced in floodplain sediments because of the high organic carbon and this decreases the vulnerability of the floodplain water for nitrate contamination in opposite to the hillslopes confining the floodplains.

\section{References}

1. A. Lang and S. Nolte, Holocene, vol. 9, no. 2, pp. 207-214, (1999)

2. M. Fuchs, M. Will, E. Kunert, S. Kreutzer, M. Fischer, and R. Reverman, Holocene, vol. 21, no. 7, pp. 1093-1104, (2011)

3. H.O. Venterink, E. Hummelink, and M. W. Van Den Hoorn, Biogeochemistry, vol. 65, no. 2, pp. 233-244, (2003)

4. C.A. J. Appelo and D. Postma, Geochemistry, groundwater and pollution (Taylor \& Francis, Layden, 2005)

5. U. Maier, M. Flegr, H. Rügner, and P. Grathwohl, Environ. Earth Sci., vol. 69, no. 2, pp. 429-441, 2013

6. LUBW, "Landesanstalt für Umwelt, Messungen und Naturschutz BadenWürttemberg," (2011). [Online]. 2011.pdf. [Accessed: 15-Apr-2017]

7. B. Selle, M. Schwientek, and G. Lischeid, J. Hydrol., vol. 486, pp. 31-38, (2013)

8. E. Kortunov, Reactive transport and long-term redox evolution at the catchment scale," (Universität Tübingen, Tubingen, 2018) 